\title{
A potential role of fecal oxalate-degrading activity in oxalate homeostasis in end-stage renal disease patients; a descriptive pilot study
}

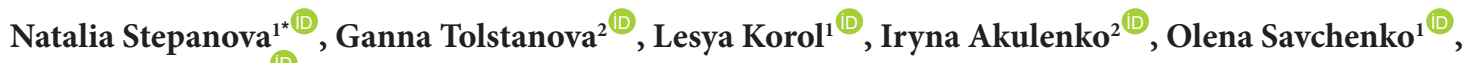 \\ Mykola Kolesnyk ${ }^{1}$
}

${ }^{1}$ State Institution "Institute of Nephrology of the National Academy of Medical Sciences of Ukraine", Kyiv, Ukraine ${ }^{2}$ Taras Shevchenko National University of Kyiv, Kyiv, Ukraine

\section{A R T I C L E I N F O}

Article Type:

Original

\section{Article History:}

Received: 9 December 2020

Accepted: 6 February 2021

Published online: 12 March 2021

\section{Keywords:}

Oxalic acid

Hyperoxaluria

Fecal microbiota

End-stage renal disease

Total oxalate-degrading activity

Oxalate homeostasis

\begin{abstract}
A B S T R A C T
Introduction: End-stage renal disease (ESRD) patients have significant differences in plasma oxalic acid (POx) concentration under the same treatment conditions.

Objectives: In the present study, we adopted the method of redoximetric titration with a $\mathrm{KMnO} 4$ solution to evaluate the effect of total fecal oxalate-degrading activity (ODA) on oxalate homeostasis in ESRD patients which has never been reported before.

Patients and Methods: A total of 56 participants were enrolled in this cross-sectional pilot study, including 24 healthy volunteers (a control reference group) and 32 ESRD patients. Among the ESRD patients, there were 21 hemodialysis (HD) and 11 peritoneal dialysis (PD) patients. Total ODA in fecal samples as well as POx concentration, daily urinary oxalate (UOx) and PD effluent oxalate excretion were determined. Cohen's $d$ was computed to calculate the effect size using post-hoc analysis.

Results: Total ODA in fecal microbiota ranged from -23 to $24 \% / 0.01 \mathrm{~g}$ of feces and was statistically higher in healthy volunteers compared with the ESRD patients. The ESRD patients with positive total fecal ODA status had higher UOx excretion level and lower POx concentration compared with the patients with negative total fecal ODA status. Cohen's $\mathrm{d}$ effect size was 1.99 and 1.05, respectively. Total fecal ODA was an independent risk factor associated with POx elevation in the ESRD patients.

Conclusion: Our pilot study firstly demonstrated a potential role of total fecal ODA in oxalate homeostasis in ESRD patients. The results might be useful for determining sample size considerations and providing groundwork for future research projects.
\end{abstract}

Implication for health policy/practice/research/medical education:

- The method of redoximetric titration with a $\mathrm{KMnO} 4$ solution is a new approach to the determination of total ODA in fecal microbiota.

- Total ODA in fecal microbiota is statistically higher in the healthy volunteers compared with ESRD patients. PD patients have a significantly lower total fecal ODA compared with HD patients.

- Total fecal ODA is an independent risk factor associated with plasma oxalic acid elevation in ESRD patients.

Please cite this paper as: Stepanova N, Tolstanova G, Korol L, Akulenko I, Savchenko O, Kolesnyk M. A potential role of fecal oxalate-degrading activity in oxalate homeostasis in end-stage renal disease patients; a descriptive pilot study. J Renal Inj Prev. 2021; 10(3): e19. doi: 10.34172/jrip.2021.19.

\section{Introduction}

Oxalate is dicarboxylic acid anion $\left(\mathrm{C}_{2} \mathrm{O}_{4} \mathrm{H}_{2}\right)$ formed in the body from a combination of exogenous (dietary supply) and endogenous (hepatic metabolism) sources (1-3). In healthy individuals, oxalate balance is achieved due to its renal excretion (up to 90\%) and intestinal absorption $(10 \%)(2,3)$. Hyperoxalemia is a well-established feature in end-stage renal disease (ESRD) patients on the grounds that oxalate is mainly excreted by the kidneys. Therefore, renal replacement therapy (RRT) is the only option to significantly lower plasma oxalate (POx) concentration in ESRD patients $(2,4)$. However, few data are available on oxalate homeostasis in dialysis patients, and there are hardly any studies on the difference in oxalate removal 
between two dialysis modalities. Several early studies have indicated higher POx level in hemodialysis (HD) patients compared with peritoneal dialysis (PD) patients $(5,6)$.

Despite the potential toxicity of oxalate, humans lack the oxalate- metabolizing enzymes (1,3). Gut microbiota is considered as an important factor affecting oxalate handling in the intestine and kidney stone formation (79). A direct correlation between Oxalobacter formigenes and calcium oxalate kidney stone diseases has been discovered $(7,8,10)$. It has been demonstrated the ability of $O$. formigenes to degrade oxalate in the intestine and stimulate its endogenous secretion $(7,10)$. Nevertheless, the absence of intestinal $O$. formigenes colonization is not the sole cause for stone disease (10-12). A diversity of gut oxalate-degrading bacteria (ODB) (e.g. Lactobacillus spp., Bifidobacterium spp., Bacillus spp., Enterococcus faecalis, Neotoma. albigula) has been hypothesized to play a role in this process $(9,13,14)$. The deficiency of ODB in the gut due to the antibiotic treatment is considered as one of the potential causes for upregulation of intestinal oxalate absorption (15-18). Most of the existing studies are based on the quantitative determination of ODB in coprofiltrates. However, the quantitation methods independently of them assess way (bacteriological, molecular, etc) could estimate the strains number but not their total fecal oxalate-degrading activity (ODA) $(1,10)$.

Total ODA is conservatively estimated as the difference between radioactive $\left[{ }^{14} \mathrm{C}\right]$-oxalate consumed and $\left[{ }^{14} \mathrm{C}\right]-$ oxalate excreted in feces and urine (19). Isolation of microbial pure culture is routinely used to estimate total ODA in fecal microbiota $(14,20)$. Only one study has attempted to measure total ODA directly in fecal samples from patients with a jejunoileal bypass diluted in anaerobic dilution solution with $\left[{ }^{14} \mathrm{C}\right]$-oxalate $(21)$. Moreover, until recently, no data has been found that surveyed total fecal ODA in ESRD patients. In addition, to date, there has been a general lack of research on association between total fecal ODA and oxalate homeostasis in dialysis patients.

\section{Objectives}

The present pilot trial aimed to design an evaluation approach for estimation of total ODA in fecal microbiota by using the method of redoximetric titration with a KMnO4 solution (radioactive oxalate was not used) without isolation of microbial pure culture and characterize its levels in ESRD patients. Furthermore, we tested the hypothesis; 1) whether the association between total fecal ODA and oxalate homeostasis existed; 2) whether the obtained results could be used in a future prospective cohort.

\section{Patients and Methods}

\section{Study design}

In this cross-sectional observational pilot investigation, a total of 56 participants were enrolled, including 32 ESRD patients without dietary oxalate restriction aged 18 years or older and 24 healthy volunteers on a free-choice diet, who served as a control reference group for evaluation of total ODA in fecal microbiota. Among the ESRD individuals, there were 21 hemodialysis (HD) and $11 \mathrm{PD}$ patients who completed three months of regular dialysis.

Inclusion criteria for the enrolment in the study were; age $>18$ years old, dialysis treatment for at least three months, a stable clinical condition and adequately functioning arteriovenous fistula or peritoneal access. In addition, the enrolled the patients had a target level of Kt/V (Kt/V urea $\geq 1.4$ for the HD patients and weekly Kt/V $\geq 1$.7 for the PD patients) and did not take antibiotics and/or probiotics for at least past 3 months.

Exclusion criteria were hospitalization in the preceding three months, previous history or actual diagnosis of peritonitis, anemia, systemic and malignant diseases, acute inflammation processes, immunosuppressive treatment and active hepatitis.

\section{Dialysis prescription}

All participants underwent their routine prescribed dialysis treatment. The HD patients were routinely dialyzed with bicarbonate-based dialysate, volumetric ultrafiltration control, and single-use synthetic (polysulphone) dialyzers at median blood flow rate of $300 \mathrm{~mL} / \mathrm{min}$ and dialysate flow rate of $500 \mathrm{~mL} / \mathrm{min}$ for 4 hours per session three times a week. Heparin was used as a standard anticoagulant. $\mathrm{HD}$ was conducted setting the target single-pool Kt/V urea $\geq 1.4$ in accordance with KDOQI guideline (National Kidney Foundation Kidney Disease Outcomes Quality Initiative Clinical Practice Guidelines for Hemodialysis Adequacy).

The PD patients were treated with continuous ambulatory PD with usual dwell time (4-5 hours during the daytime and 8-10 hours at night). All patients received commercially available glucose-based Dianeal PD solution (Baxter Healthcare SA, Castlebar, Ireland) of various strengths $(1.36 \%, 2.27 \%)$ and icodextrin. Dialysis prescription was guided by the target to achieve a value of total weekly $\mathrm{Kt} / \mathrm{V} \geq 1.7$ in accordance with the National Kidney Foundation Kidney Disease Outcomes Quality Initiative Clinical Practice Guidelines for PD Adequacy.

\section{Clinical and routine laboratory measurements}

Patient demographic data consisting age, gender, comorbid conditions and medication use were obtained from the medical records of patients at our hospital. All blood, urine and feces samples were collected after the longest dialytic interval in the HD patients and during the clinic visit at the time of PDE (peritoneal dialysate effluent) collection in the PD treated patients. Whole blood samples were gathered from the participants after an overnight fast during the time of the routine outpatient visit. The blood samples were processed immediately after sampling.

Routine biochemical parameters consisting blood and 
daily dialysate concentration of urea and creatinine, serum albumin, C-reactive protein (CRP), glucose, electrolytes, and lipid profile parameters were conducted using an automatic analyzer "Flexor junior" (Vital Scientific, Netherlands). Hematological parameters of blood were determined using an "ABX Micros-60" (Horiba Medical, France).

Body mass index (BMI) was calculated as weight in kilograms divided by the square of the height in meters. Glomerular filtration rate (GFR, milliliters per minute per $1.73 \mathrm{~m}^{2}$ ) was calculated using the Chronic Kidney Disease Epidemiology Collaboration (CKD-EPI) formula. Anuria was defined as 24-hour urine volume of less than $100 \mathrm{~mL}$ in two consecutive measurements. Residual renal function (RRF) was measured by the calculation of urea and creatinine clearance from a 24-h urine collection using the following standard formula:

$\operatorname{RRF}\left[\mathrm{mL} / \mathrm{min} / 1.73 \mathrm{~m}^{2}\right]=$

$1 / 2\left[\frac{\text { Urine } \operatorname{Cr}(\mu \mathrm{mol} / \mathrm{L})}{\operatorname{Serum~} \operatorname{Cr}(\mu \mathrm{mol} / \mathrm{L})}+\frac{\text { Urine Ur }(\mathrm{mmol} / \mathrm{L})}{\text { Serum } \operatorname{Ur}(\mathrm{mmol} / \mathrm{L})}\right] \times \frac{\text { Urine Volume }(\mathrm{mL})}{1440}$.

\section{Oxalate homeostasis measurements}

POx concentration was measured spectrophotometrically using a commercially available kit (MAK315, Sigma, Spain) according to the manufacturers' protocols. Predialysis plasma samples were collected from the HD patients.

Daily urinary oxalate (UOx) excretion and PDE oxalate concentration (PDEox) were determined using an oxalate oxidase/peroxidase reagent (BioSystems, Spain). All PDE samples for oxalate assessment were obtained from overnight PDE collection (with an exchange of $2 \mathrm{~L}$ of $1.36 \%$ or $2.27 \%$ glucose dialysate) at the night preceding the test.

\section{Determination of total ODA in feces}

Fecal samples were collected from the study individuals in provided containers in the morning of sample delivery. Upon arrival at our hospital (within 4 hours of defecation), $0.01 \mathrm{~g}$ feces were cultured in highly selective media Oxalate Medium (g/L): K2HPO4 - 0.25, KH2PO4 - 0.25, (NH4)2SO4-0.5, MgSO $4.7 \mathrm{H} 2 \mathrm{O}-0.025, \mathrm{CH} 3 \mathrm{COON}-$ 0.82 , yest extract -1.0 , resazurin $-0,001, \mathrm{Na} 2 \mathrm{CO} 3-4$, L-cysteine-HCl - 0,5, Trace element solution SL-10 - 1 $\mathrm{mL}(\mathrm{mix} / \mathrm{L}: \mathrm{HCl}(25 \% ; 7.7 \mathrm{M})-10.00 \mathrm{~mL}, \mathrm{FeCl} 2 \mathrm{x} 4 \mathrm{H} 2 \mathrm{O}$ - 1.50 g, $\mathrm{ZnCl} 2$ - $70.00 \mathrm{mg}, \mathrm{MnCl} 2 \times \mathrm{H} 2 \mathrm{O}-100.00 \mathrm{mg}$, $\mathrm{H} 3 \mathrm{BO} 3-6.00 \mathrm{mg}, \mathrm{CoCl} 2 \times 6 \mathrm{H} 2 \mathrm{O}-190.00 \mathrm{mg}, \mathrm{CuCl} 2 \mathrm{x}$ $2 \mathrm{H} 2 \mathrm{O}-2.00 \mathrm{mg}, \mathrm{NiCl} 2 \times 6 \mathrm{H} 2 \mathrm{O}-24.00 \mathrm{mg}, \mathrm{Na} 2 \mathrm{MoO} 4 \mathrm{x}$ $2 \mathrm{H} 2 \mathrm{O}-36.00 \mathrm{mg}$; Na2C2O4 - $5 \mathrm{mg}$ ) (22) and cultivated anaerobically at $37^{\circ} \mathrm{C}$ for 48 hours (test solution). The method of redoximetric titration with a $\mathrm{KMnO} 4$ solution was adopted to evaluate total ODA in fecal microbiota. In 48 hours, a $10 \mathrm{~mL}$ aliquot of test solution or $10 \mathrm{~mL}$ of Oxalate Medium (control) was centrifuged at $3000 \mathrm{~g}$ for 15 minutes, $\mathrm{T}_{\text {room }} .10 \mathrm{~mL}$ of supernatant was transferred to a $50 \mathrm{~mL}$ beaker. Calcium oxalate was precipitated from the samples by adding $10 \mathrm{~mL}$ of $0.4 \mathrm{M} \mathrm{Ca}(\mathrm{NO} 3) 2$. The precipitate formed was filtered through double paper filters with low filtration rate $\left(80 \mathrm{~g} / \mathrm{m}^{2}\right)$. The filtrate was discarded. Precipitated calcium oxalate was dissolved with $25 \mathrm{~mL}$ of $\mathrm{H} 2 \mathrm{SO} 4$ (1:4). Around $10 \mathrm{~mL}$ of acidified calcium oxalate solution was mixed with $20 \mathrm{~mL}$ deionized water and heated to $80^{\circ} \mathrm{C}$ prior to titration. About $10 \mathrm{~mL}$ of $\mathrm{H} 2 \mathrm{SO} 4$ (1:4) solution was immediately added and titrated with $\mathrm{KMnO} 4(0.02 \mathrm{~N})$ solution until a pink color persisted for 30 seconds. The results were expressed as $\%$ of oxalate degradation per $0.01 \mathrm{~g}$ of feces.

\section{Ethical issues}

This cross-sectional observational pilot study was a part of an ongoing institute's research work "Effect of oxalate and urate metabolism on the evolution of kidney disease" (ClinicalTrials.gov Identifier: NCT04399915, Domestic Trial Registration Number 0119U000002; https:// clinicaltrials.gov/ct2/show/NCT04399915). The study was carried out in accordance with the Declaration of Helsinki and conducted between January 2018 and May 2020. The study protocol was confirmed by the Ethics Committee of the Institute (Protocol Number; 8/2017 from September $19,2017)$. Writing informed consent was obtained from all subjects participating in the study.

\section{Statistical analysis}

This study was strictly exploratory and descriptive in nature. A priori power analysis was impossible because the pilot data were not available. However, we determined a sample size of 56 participants based on the capacity of a commercially available POx kit used in the study (the average of 2 measurements was used).Analysis and all graphs were performed using MedCalc (Belgium). The average means $(\mathrm{M})$ and the standard deviations $(\mathrm{SD})$ or the median $(\mathrm{Me})$ and the interquartile ranges [Q25-Q75] were calculated according to a distribution. For the statistical analysis, we used the Student's t-test and the nonparametric (U-test) Mann-Whitney U test, respectively. Categorical variables were expressed as proportions. The chi-square tests $\left(\chi^{2}\right)$ were used to compare two groups. The Spearman's correlation test was used to evaluate the association between total fecal ODA and oxalate homeostasis parameters. Receiver operating characteristic (ROC) curve analysis was performed to assess the overall discriminative ability of total fecal ODA measured by using the redoximetric titration method to predict the POx elevate above average, and to establish its optimal cutoff point. Univariate and multivariate logistic regression analyses were fitted to assess the factors affecting POx concentration in the ESRD patients. The strength of the association between POx and potential confounding factors was expressed as odds ratio (OR) and 95\% confidence interval (CI).

Cohen's $\mathrm{d}$ and $\rho$ effect sizes in post-hoc tests were 
computed to determine differences in oxalate homeostasis between the groups and calculate the required sample sizes in the correlation analysis. In addition, due to a small statistical power in the difference in POx concentrations between the groups, we determined the required sample size using Cohen's d-values in post-hoc test for future large-scale research. The effect size calculators for two independent groups (mean \pm SD) with different sample sizes and the non-parametric Mann-Whitney $U$ tests were applied according to the distribution. Post-hoc power analysis was performed using $\mathrm{G}^{*}$ Power software, version 3.1.9.4.

\section{Results}

\section{Baseline characteristics of the study participants}

The baseline characteristics of the study participants are shown in Table 1. As presented in Table 1, the control and the dialysis groups did not differ in age or gender distribution. However, as expected, significant differences in the majority of all clinical and laboratory markers were observed in the dialysis patients compared with the healthy volunteers.

Total ODA in fecal microbiota and oxalate homeostasis parameters in ESRD patients compared with the healthy volunteers

Total ODA in fecal microbiota ranged from -23 to 24 $\% / 0.01 \mathrm{~g}$ of feces and was statistically higher in the healthy volunteers compared with the ESRD patients (Figure 1).

Negative total ODA in fecal microbiota $(\leq 0 \% / 0.01 \mathrm{~g})$

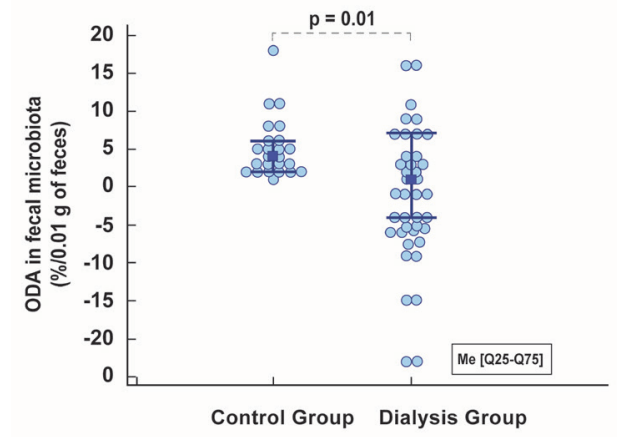

Figure 1. Total fecal ODA in the ESRD patients and the control group.

was observed in 16/32 (50\%) dialysis patients and there were no subjects with negative ODA status among healthy volunteers $\left(\chi^{2}=16.5, P<0.001\right)$. The ESRD patients had a significantly high POx concentration compared with the control group: 42.0 [26.6-51.3] versus 28.3 [24.6-35,7] $\mu \mathrm{mol} / \mathrm{L}(P=0.01)$. However, no difference was found in 24-hour UOx excretion between the dialysis patients with preserved diuresis and healthy volunteers: 57.2 [42-66.6] versus 46.5 [33.4-60.9] $(P=0.08)$.

Association between total fecal ODA status and oxalate homeostasis in ESRD patients

The average levels of pre-dialysis POx concentration and daily UOx excretion were 4.03 [2.5-4.6] $\mathrm{mg} / \mathrm{L}$ and $49.8 \pm$ $17.9 \mathrm{mg} / \mathrm{d}$, respectively. The PD patients had significantly lower values of 24-hour UOx excretion and total ODA in

Table 1. Demographic and clinical characteristics of the healthy volunteers and the ESRD patients

\begin{tabular}{|c|c|c|c|}
\hline Parameters & Healthy volunteers $(n=24)$ & A total of dialysis patients $(n=32)$ & $P$ value \\
\hline Male gender, $\mathrm{n}(\%)$ & $10(41.6 \%)$ & $20(62.5 \%)$ & 0.12 \\
\hline Age, years & $46.9 \pm 11.9$ & $48.4 \pm 13.3$ & 0.58 \\
\hline Dialysis vintage at this study entry, months & - & $30(22-76.5)$ & - \\
\hline Diabetics, n (\%) & - & $10(31.2 \%)$ & - \\
\hline $\mathrm{BMI}, \mathrm{kg} / \mathrm{m}^{2}$ & $26.8 \pm 4.0$ & $25.9 \pm 4.4$ & 0.64 \\
\hline Anuria, n (\%) & - & $11(34.4 \%)$ & - \\
\hline $\mathrm{RRF}, \mathrm{mL} / \mathrm{min} / 1.73 \mathrm{~m}^{2}$ & $73.3(62.0-78.4)$ & $5.0(4.0-6.0)$ & $<0.0001$ \\
\hline Serum albumin, g/L & $42.8(41.3-45.1)$ & $40.0(36.6-40.9)$ & $<0.0001$ \\
\hline Total blood protein, $\mathrm{g} / \mathrm{L}$ & $69.5 \pm 3.9$ & $62.2 \pm 6.5$ & $<0.0001$ \\
\hline Systolic blood pressure, $\mathrm{mm} \mathrm{Hg}$ & $115(101-125)$ & $140(134-145)$ & $<0.0001$ \\
\hline Diastolic blood pressure, $\mathrm{mm} \mathrm{Hg}$ & $79.0(66.2-82.0)$ & $90(85-90)$ & $<0.0001$ \\
\hline $\mathrm{Hb}, \mathrm{g} / \mathrm{L}$ & $125.1 \pm 10.5$ & $108.2 \pm 15.9$ & 0.0001 \\
\hline Glucose, $\mathrm{mmol} / \mathrm{L}$ & $4.9(4.2-5.3)$ & $5.3(4.5-5.8)$ & 0.37 \\
\hline Calcium, mmol/L & $2.4(2.3-2.5)$ & $2.2(2.17-2.45)$ & 0.02 \\
\hline Phosphorus, $\mathrm{mmol} / \mathrm{L}$ & $1.1 \pm 0.1$ & $1.9 \pm 0.7$ & $<0.0001$ \\
\hline iPTH, ng/L & - & $294.5(184.0-437.0)$ & \\
\hline Uric acid, $\mathrm{mmol} / \mathrm{L}$ & $266(162.8-375.6)$ & $326.5(278.8-387.7)$ & 0.008 \\
\hline $\mathrm{TC}, \mathrm{mmol} / \mathrm{L}$ & $4.9 \pm 0.96$ & $5.6 \pm 1.6$ & 0.08 \\
\hline Triglyceride, $\mathrm{mmol} / \mathrm{L}$ & $1.1(0.8-1.6)$ & $1.6(1.16-2.5)$ & 0.01 \\
\hline
\end{tabular}

Abbreviations: BMI, body mass index; $\mathrm{Hb}$, hemoglobin; $\mathrm{PTH}$, intact parathyroid hormone; RRF, renal residual function; TC, total cholesterol. The values are expressed as mean \pm standard deviation (SD) or as the median and interquartile range [Me (Q25-Q75)]. The values are compared between the groups using the Chi-square tests, the Student's $t$ test and the Mann-Whitney $U$ test as appropriate. $* P<0.01$ versus a total of dialysis patients group. 
Table 2. Oxalate homeostasis parameters and total ODA in fecal microbiota according to dialysis modality

\begin{tabular}{|c|c|c|c|c|}
\hline Oxalate homeostasis parameters & All $(n=32)$ & HD patients $(n=21)$ & PD patients $(n=11)$ & $P$ \\
\hline Predialysis POx, mg/L & $4.03[2.5-4.6]$ & $3.8[2.5-4.6]$ & $4.3[2.6-4.5]$ & 0.79 \\
\hline UOx, mg/d & $49.8 \pm 17.9$ & $59.4 \pm 12.0$ & $39.3 \pm 17.8$ & 0.006 \\
\hline PDEox, mg/d & - & - & $27.2 \pm 16.9$ & - \\
\hline Total ODA in fecal microbiota, \%/0.01 g of feces & $0.5[-4.5-8]$ & $3.0[-1-12.5]$ & $-4[-6.5-3]$ & 0.03 \\
\hline
\end{tabular}

Abbreviations: POx, plasma oxalate; UOx, urinary oxalate; PDEox, peritoneal dialysis effluent oxalate concentration; ODA, oxalate-degrading activity.

The values are expressed as mean \pm standard deviation $(\mathrm{M} \pm \mathrm{SD}$ ) or as the median and interquartile range (Me [Q25-Q75]). The values are compared between the groups using the Student's $t$ test and the Mann-Whitney $U$ test as appropriate.

fecal microbiota compared with the HD patients (Table 2).

Moreover, total fecal ODA in the ESRD patients was directly associated with daily UOx excretion $(r=0.6$, $P=0.003$ ) and had an inverse correlation with POx concentration $(r=-0.62, P<0.0001$; Figure 2).

We did not find a significant association between total fecal ODA and oxalate concentrations in PDE in the PD patients $(r=-0.37, P=0.25)$. However, power analysis indicated that a sample size of 25 patients would be sufficient to detect a significant association between total fecal ODA and PDEox with an alpha of 0.05, a large effect size $(\rho=0.6)$ and power of 0.95 .

It should be noted, that the ESRD patients with anuria

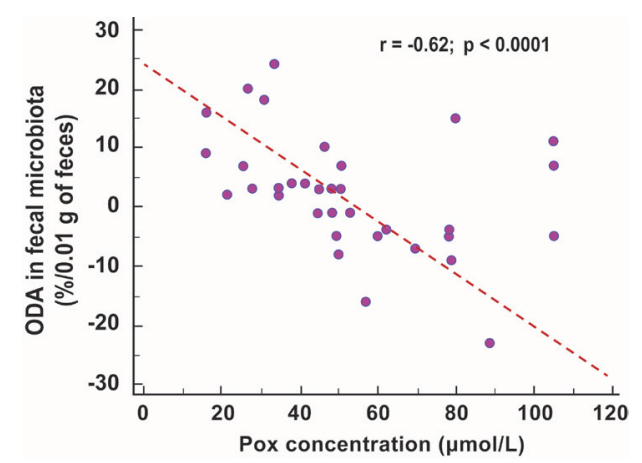

Figure 2. Association between total fecal ODA and POx concentrations in ESRD patients.

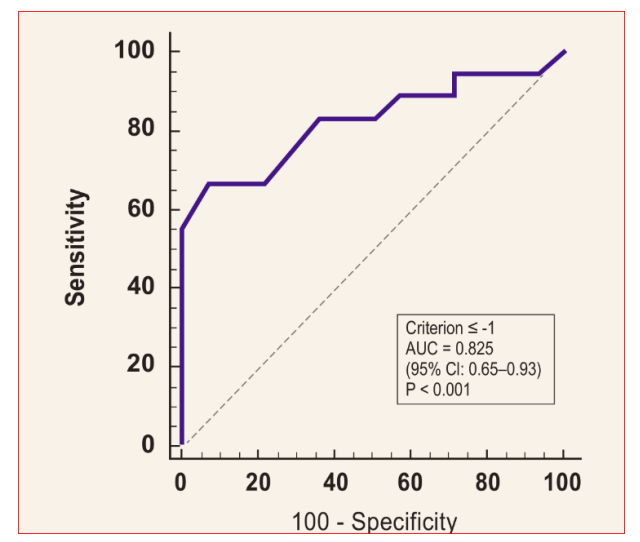

Figure 3. Receiver operating characteristic (ROC) curve for the cut-off value of total fecal ODA for predicting POx concentration of $>4.03 \mathrm{mg} / \mathrm{L}$. had a higher POx concentration compared to the patients with preserved diuresis: 4.5 [3.6-6.6] versus 3.4 [2.07-4.6] $\mathrm{mg} / \mathrm{L}(P=0.04)$. However, total fecal ODA did not differ between anuria and preserved diuresis groups; 3 [-5-7] versus $3[-1 ; 9.7] \% / 0.01 \mathrm{~g}(P=0.34)$. Subgroup analysis among the anuric and preserved diuresis patients was not performed due to the small sample size of the entire cohort.

To further assess the clinical significance of total fecal ODA in increasing POx concentration $>4.03 \mathrm{mg} / \mathrm{L}$ (according to POx average level in our dialysis cohort), we performed ROC analysis. We observed that the area under the curve (AUC) of total fecal ODA with the ability to discriminate POx concentration was 0.825 (95\% CI: $0.65-0.93)$. The optimal cut-off value for total fecal ODA as a predictor for POx concentration of $>4.03 \mathrm{mg} / \mathrm{L}$ was determined to be $\leq-1 \% / 0.01 \mathrm{~g}$ of feces (sensitivity of $66.7 \%$ and specificity of $92.8 \%$; Figure 3 ).

Additionally, the ESRD patients were allocated into two groups according to total fecal ODA status; group 1 - 16 (50\%) ESRD patients with positive total fecal ODA status ( $\geq 1 \%$ of oxalate degradation per $0.01 \mathrm{~g}$ of feces) and group 2-16 (50\%) ESRD patients with negative total fecal ODA status ( $\leq-1 \%$ of oxalate degradation per $0.01 \mathrm{~g}$ of feces).

Higher POx concentration and lower UOx excretion were diagnosed in the patients of group two compared with the patients of group 1 (Figure 4).

To determine whether the observed results were a type I error, we conducted post-hoc power analysis. The

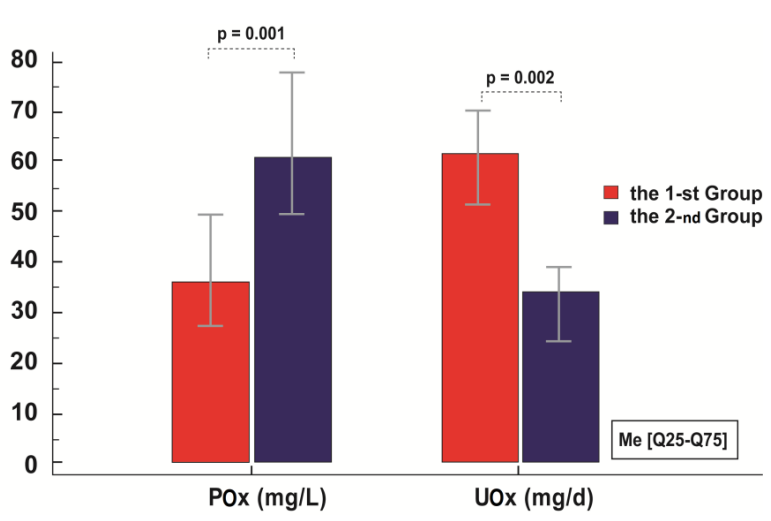

Figure 4. Plasma and urine oxalate concentrations according to total fecal ODA status in ESRD patients. 
analysis demonstrated that while predicted power (1- $\beta$ error probability) was of 0.87 suggesting an appropriate sample size for the comparison of UOx excretion between the groups (Cohen's $\mathrm{d}=1.99$ ), low power of 0.48 (Cohen's $\mathrm{d}=1.05$ ) was defined for detecting the difference between POx concentrations that indicated a false-positive result. In the statistical context, a minimum sample of 60 participants was required to observe a statistically significant difference in POx with alpha of 0.05 (twotailed), large effect size and power (1- $\beta$ error probability) of 0.95 .

Univariate logistic regression analysis was performed to identify the factors contributed to POx concentration elevation in the ESRD patients. The factors identified as significant in the univariate logistic regression analysis were further included in the multivariate logistic regression model to control the confounding effects of the factors associated with POx concentration $>4.03 \mathrm{mg} / \mathrm{L}$. It showed that total fecal ODA remained an independent risk factor associated with POx elevation in the ESRD patients (Table 3).

\section{Discussion}

Oxalate in healthy subjects is eliminated through urine excretion (85\% to $90 \%$ ), forming insoluble calcium oxalate and elimination in feces or degradation by the gastrointestinal (GIT) oxalate-degrading bacteria (15\% to $10 \%)(1,8)$. Elevated POx concentration and decreased UOx excretion levels are associated with the progression of chronic kidney disease (CKD) (23-25). In uremic and/ or anuric conditions, dialysis assumes the main approach for oxalate removal $(2,4,24)$. Nevertheless, despite a homogenous patient population and the standardized dialysis regimen, intraindividual predialysis $\mathrm{POx}$ concentration level varies from $1.8 \mathrm{mg} / \mathrm{L}(20 \mu \mathrm{mol} / \mathrm{L})$ to $5.4 \mathrm{mg} / \mathrm{L}(60 \mu \mathrm{mol} / \mathrm{L})$ in different research $(2,24$ 26). Considering the fact that oxalate homeostasis only marginally depends on dietary oxalate intake (8) and cannot be excreted by the kidneys in ESRD patients, an issue arises why ESRD patients have significant differences in
POx concentration under the same treatment conditions. In this context, we hypothesized that oxalate elimination could be compensated by GIT and might depend on both paracellular and transcellular oxalate transport pathways across the intestine as well as total ODA in fecal microbiota in dialysis patients. In the present study, we focused on total ODA in fecal microbiota and attempted to characterize its level in a small cohort of the dialysis patients using the method of redoximetric titration with a $\mathrm{KMnO} 4$ solution. In addition, we evaluated effect of total fecal ODA on oxalate homeostasis in ESRD patients which has never been reported before. The present study has several new findings.

First, we confirmed the accuracy and reliability of the method of redoximetric titration with a $\mathrm{KMnO} 4$ solution to evaluate total ODA level in fecal microbiota incubated in Oxalate Medium. Previous evidence of ODB in fecal microbiota was generally based on $O$. formigenes quantification obtained using bacteriological culture, real-time PCR or molecular techniques such as $16 \mathrm{~S}$ rRNA microbial profiling analysis $(1,8,10)$. Moreover, the ability of different Lactobacillus and Bifidobacterium strains to degrade oxalate has been demonstrated in vitro using quantitative ODB measurement $(14,20)$. However, the quantitation methods independently of them assess way (bacteriological, molecular, etc) could estimate the strains number but not their total fecal ODA $(1,10)$. In the present study, we analyzed total ODA in normalized amount of feces which indicated total ODA function in fecal microbiota independently of strains and bacteria numbers. It should be emphasized, that our results could not be compared directly with the findings of other research as far as, at present, there still have been no previous studies examining this issue in ESRD patients, and a different approach for measuring total fecal ODA was used only in kidney stone disease patients. Nonetheless, our preliminary results clearly demonstrated the potential for evaluation of total ODA in fecal microbiota without the need for isolation of microbial pure culture and costly specific assay or radioactive tags.

Table 3. Risk factors associated with POx concentration in the ESRD patients in univariate and multivariate logistic regression analysis

\begin{tabular}{|c|c|c|c|c|c|c|}
\hline \multirow{2}{*}{ Variables } & \multicolumn{3}{|c|}{ Univariate } & \multicolumn{3}{|c|}{ Multivariate } \\
\hline & OR & $95 \% \mathrm{Cl}$ & $P$ value & OR & $95 \% \mathrm{Cl}$ & $P$ value \\
\hline Gender (male vs female) & 0.27 & $0.09 ; 0.83$ & 0.01 & 0.51 & $0.06 ; 4.4$ & 0.54 \\
\hline Dialysis modality (HD versus PD) & 0.16 & $0.05 ; 0.67$ & 0.002 & 0.39 & $0.01 ; 17$ & 0.61 \\
\hline $\mathrm{BMI}, \mathrm{kg} / \mathrm{m}^{2}$ & 1.2 & $1.06 ; 1.4$ & 0.002 & 1.3 & $1.02 ; 1.7$ & 0.03 \\
\hline Anuria & 3.5 & $1.2 ; 10.3$ & 0.02 & 1.6 & $0.99 ; 2.1$ & 0.09 \\
\hline $\operatorname{RRF}\left(\mathrm{mL} / \mathrm{min} / 1.73 \mathrm{~m}^{2}\right)$ & 0.86 & $0.78 ; 0.98$ & 0.04 & 0.88 & $0.82 ; 0.99$ & 0.05 \\
\hline Total ODA in fecal microbiota, $\% / 0.01 \mathrm{~g}$ of feces & 0.87 & $0.8 ; 0.94$ & $<0.0001$ & 0.76 & $0.61 ; 0.94$ & 0.01 \\
\hline Triglyceride, $\mathrm{mmol} / \mathrm{L}$ & 2.07 & $1.05 ; 4.1$ & 0.01 & 1.3 & $1.1 ; 2.9$ & 0.03 \\
\hline $\mathrm{HDL}-\mathrm{C}, \mathrm{mmol} / \mathrm{L}$ & 0.13 & $0.03 ; 0.63$ & 0.006 & 0.21 & $0.09 ; 1.09$ & 0.07 \\
\hline Calcium, mmol/L & 41 & $1.2 ; 136$ & 0.04 & 27 & $0.61 ; 87$ & 0.22 \\
\hline
\end{tabular}

Abbreviations: BMI, body mass index; $\mathrm{Cl}$, confidence interval; HR, hazard ratio; HD, hemodialysis; HDL-C, high-density lipoprotein cholesterol; PD, peritoneal dialysis; RRF, residual renal function; SD, standard error. 
Second, we found a significantly lower total fecal ODA level in PD patients compared with HD patients. It has been observed that there are noteworthy differences in fecal microbiota between ESRD patients and healthy subjects and RRT modality affects its composition and function (27-29). Overall, the GIT microbiota is characterized by the predominance of both aerobic (E. coli, K. pneumoniae, Enterococcus) and anaerobic (Clostridium perfringens) organisms in dialysis patients (29). In addition, ESRD patients showed low colonization of Bifidobacterium and Lactobacillus species (27-29) which could crucially affect total fecal ODA. However, the differences in taxonomic composition in fecal microbiota between HD and PD patients are still far from being fully understood. Stadlbauer et al (28) have analyzed specific effects of HD and PD treatment on fecal microbiome composition and function. The authors observed more pronounced dysbiosis in $\mathrm{HD}$ patients compared with PD patients. Conversely, in a recent study, $\mathrm{Hu}$ et al (30) have demonstrated that gut microbiota diversity is lower in PD patients compared with HD patients. In turn, loss of bacterial biodiversity is known to be consequence of intestinal dysbiosis $(3,27,28)$. In the context of dysbiosis, the only possible explanation for greater total fecal ODA loss in PD patients compared with HD patients may be the frequent use of antibiotic therapy for $\mathrm{PD}$-associated infections (31). Significant contribution of ODB to oxalate homeostasis (reducing oxalate absorption and subsequent urinary excretion) after antibiotic treatment has been profoundly described (15-18). Georgieva et al (29) have highlighted that most strains of the Lactobacillus and Bifidobacterium group are susceptible to the main antibiotic classes. Tasian and colleagues (16) have identified a strong association between oral antibiotics and the risk of nephrolithiasis which remains elevated for up to five years from antibiotic exposure. These results also accord with our earlier studies, which reported a strong association between antibiotics administration, intestinal barrier dysfunction and hyperoxaluria formation $(15,18,25)$. In view of all that has been mentioned so far, one may suppose that Lactobacillus and Bifidobacterium deficiency leads to intestinal barrier dysfunction, violation of oxalate transport mechanisms in intestinal epithelium (both secretion and absorption) and a decrease in total ODA in fecal microbiota in PD patients. Nevertheless, it is still unclear whether the use of antibiotics can affect total fecal ODA loss. Moreover, despite notwithstanding the results of the previous studies mentioned above, the interpretation of a significant decrease in total fecal ODA in PD patients compared with HD patients should not be limited only by dysbiosis. We hold the view that dialysis solution composition and intestinal glucose absorption frequency of peritoneal exchanges, antibiotic classes and other medications (as well as high intraperitoneal pressure that can promote delayed colonic transit time) should be considered as potential factors affecting total fecal ODA in future large-scale studies.

Finally, in the present study, we demonstrated a potential effect of total fecal ODA on oxalate homeostasis in ESRD patients. The results of this research indicate that the ESRD patients with positive total fecal ODA status $(\geq 1$ $\% / 0.01 \mathrm{~g}$ of feces) have higher UOx excretion level and lower POx concentration compared with the patients with negative total fecal ODA status ( $\leq-1 \% / 0.01 \mathrm{~g}$ of feces). In other words, the normal oxalate-degrading functioning ability of fecal microbiota can lead to a decrease in POx level and an increase in UOx. It should be noted that posthoc power analysis did not confirm a significant difference in POx concentrations in our samples indicating a falsepositive result. In our opinion, the small study sample size $(n=32)$ might have played a limiting role in the statistical significance, and a minimum sample size of 60 participants would be required to observe a statistically significant difference in POx concentrations.

Our data on a negative association between total ODA in fecal samples and POx concentration are consistent with the findings of a very early study by Allison et al (21). The scientists identified significantly lower rates of oxalate degradation by mixed bacterial populations in fecal samples from patients with jejunoileal bypass [0-0.006 $\mathrm{mumol} /(\mathrm{g} \mathrm{X} \mathrm{h})]$ compared with healthy subjects [0.1-4.8 mumol/(gX h)]. The most interesting and promising data on oxalate homeostasis and intestinal function are a series of studies by Hatch et al $(7,10,32)$. The authors concluded that Oxalobacter formigenes colonization reduced UOx excretion via enhancement of basal net colonic oxalate secretion. However, it is important to note that the indirect and, in fact, the opposite result was obtained in our study: the higher total ODA level in fecal microbiota in ESRD patients was, the higher UOx level occurred. This hyperoxaluric phenomenon in dialysis patients is completely different from existing data in healthy subjects and kidney stone disease patients in whom hyperoxaluria is one of the most significant risk factors for nephrolithiasis $(1,3,8)$ and CKD progression $(25,33)$. The findings observed in this study mirror those of the previous studies that have demonstrated that oxalate removal rate in ESRD patients is significantly greater compared with normal subjects $(4,5,27)$. The authors assumed that high POx concentration in dialysis patients could not be explained by its insufficient excretion, and heperoxalemia could potentially result from increased oxalate synthesis or gastrointestinal absorption in ESRD patients.

The intestine plays a complex role in oxalate homeostasis via interconnected mechanisms for intestinal epithelium oxalate transport (both secretion and absorption) and microbiota-dependent degradation of intraluminal oxalate $(1,3,7,27,29)$. Absorptive flux of oxalate across the intestine can be via both paracellular (predominantly passive) and transcellular pathways $(3,33)$. The active 
transcellular movement of oxalate is provided by anion exchange proteins belonging to the multi-functional SLC26 gene family. One of the gene family members, Slc26a6, is expressed at high levels in the intestine, renal proximal tubule and plays a major role in controlling systemic oxalate metabolism $(33,34)$. Its pivotal role in oxalate homeostasis was demonstrated in Slc26a6-/mice (34). These mice had a defect in intestinal oxalate secretion resulting in enhanced net absorption of oxalate that followed by increased serum and urine oxalate. Recently, it has been found that $O$. formigenes produces a small protein that directly induces oxalate transport via the oxalate transporter SLC26A6 -dependent mechanism in intestinal Caco-2 cells (35). Thus, increased total fecal ODA may represent both ODB numbers (e.g. O. formigenes) and their metabolic activity. We can speculate that our data on a negative association between total ODA in fecal microbiota and POx concentration may be explained by systemic effect of ODB on net oxalate transport.

\section{Conclusion}

This research has thrown up many questions in need of further investigation. Taken together, the results of our pilot cross-sectional study firstly demonstrated a potential role of total fecal ODA in oxalate homeostasis in ESRD patients. A significant association between total ODA in fecal microbiota and oxalate levels in plasma, urine and PDE is an important and fundamental issue for future research. We believe that our results might be useful for determining sample size considerations and providing groundwork for future research projects.

\section{Limitations of the study}

The present pilot study has certain limitations that should be considered in terms of interpreting our findings. First, it was a small sample size study conducted in a singlecenter, and, thus, our promising results will need to be confirmed in full-scale studies. Second, we measured total ODA in fecal microbiota, POx, PDEox and UOx excretion at the only one-time point. It is unfortunate that the study did not include measurements of the dialysate oxalate concentration in HD patients. Therefore, it did not allow us to calculate and compare oxalate removal rates depending on dialysis modality. Third, we had not restricted the patients to dietary oxalate before oxalate measurements were performed. Theoretically, it could affect the patients' POx concentration and should be considered in future large-scale research. However, it is worth noting that high-oxalate foods tend to contain high potassium and phosphate concentrations that are already contraindicated in dialysis patients. Finally, we did not take into account the mentioned above factors that could affect total ODA in fecal microbiota (dialysis solution composition, intestinal absorption of glucose, frequency of peritoneal exchanges, antibiotic classes and other medications etc). It is also worth bearing in mind that it was a cross-sectional study. Therefore, we were not able to draw predictive conclusions.

Notwithstanding these limitations, this is the first study reporting a potential role of total fecal ODA in oxalate homeostasis in ESRD patients.

\section{Acknowledgments}

We appreciated all the subjects who voluntarily participated in this study.

\section{Authors' contribution}

NS conceived the presented concept, designed the study, analyzed and interpreted the patient data, and was a major contributor in writing the manuscript. GT analyzed and interpreted the total fecal ODA data, and contributed to writing the manuscript and its general edition. LK, IA, OS and LS contributed reagents/materials/analysis tools. MK worked out the concept, research management.

\section{Availability of data and materials}

The datasets generated and analyzed during the current study are available in the Mendeley Dataset Repository: http://dx.doi.org/10.17632/yvyjgwv57h.2\#file-612b25ab4bae-4895-ab18-4b2422ae074e.

\section{Conflicts of interest}

The authors declare that they have no competing interests. The part of the data was reported and published as an abstract for a poster presentation at the 57th ERAEDTA Congress, 2020 (Milan, Italy, https://academic. oup.com/ndt/article-abstract/35/Supplement_3/gfaa142. P0176/5853473).

\section{Ethical considerations}

Ethical issues (including plagiarism, data fabrication, double publication) have been completely observed by the authors.

\section{Consent for publication}

The manuscript does not contain any personal data in any form. All the authors have approved the manuscript and agreed to its submission.

\section{Funding/Support}

This research did not receive any specific grant from funding agencies in the public, commercial, or not-forprofit sectors.

\section{References}

1. Abratt VR, Reid SJ. Oxalate-degrading bacteria of the human gut as probiotics in the management of kidney stone disease. Adv Appl Microbiol. 2010;72:63-87. doi: 10.1016/S0065-2164(10)72003-7.

2. Ermer T, Kopp C, Asplin JR, Granja I, Perazella MA, Reichel $\mathrm{M}$, et al. Impact of regular or extended hemodialysis and 
hemodialfiltration on plasma oxalate concentrations in patients with end-stage renal disease. Kidney Int Rep. 2017;2:1050-8. doi: 10.1016/j.ekir.2017.06.002.

3. Robijn S, Hoppe B, Vervaet BA, D'Haese PC, Verhulst A. Hyperoxaluria: a gut-kidney axis? Kidney Int. 2011; 80:1146-58. doi: 10.1038/ki.2011.287.

4. Prenen JAC, Mees EJD, Boer P. Plasma oxalate concentration and oxalate distribution volume in patients with normal and decreased renal function. Eur J Clin Invest. 1985;15:45-49. doi: 10.1111/j.1365-2362.1985. tb00142.x.

5. Watts RW, Veall N, Purkiss P. Oxalate dynamics and removal rates during haemodialysis and peritoneal dialysis in patients with primary hyperoxaluria and severe renal failure. Clin Sci (Lond). 1984;66:591-7. doi: 10.1042/ cs0660591.

6. Dell'Aquila R, Feriani M, Mascalzoni E, Bragantini L, Ronco C, La Greca G. Oxalate removal by differing dialysis techniques. ASAIO J. 1992;38(4):797-800.

7. Hatch M, Freel RW. The roles and mechanisms of intestinal oxalate transport in oxalate homeostasis. Semin Nephrol. 2008;28:143-51. doi: 10.1016/j.semnephrol.2008.01.007.

8. Ticinesi A., Nouvenne A., Meschi T. Gut microbiome and kidney stone disease: Not just an Oxalobacter story. Kidney Int. 2019; 96:25-7. doi: 10.1016/j.kint.2019.03.020.

9. Miller AW, Choy D, Penniston KL, Lange D. Inhibition of urinary stone disease by a multi-species bacterial network ensures healthy oxalate homeostasis. Kidney Int. 2019; 96:180-8. doi: 10.1016/j.kint.2019.02.012.

10. Hatch M, Cornelius J, Allison M, Sidhu H, Peck A, Freel RW. Oxalobacter sp. reduces urinary oxalate excretion by promoting enteric oxalate secretion. Kidney Int. 2006; 69:691-8. doi:10.1038/sj.ki.5000162.

11. Sikora P, Niedźwiadek J, Mazur E, Paluch-Oleś J, Zajaczkowska M, Kozioł-Montewka M. Intestinal colonization with Oxalobacter formigenes and its relation to urinary oxalate excretion in pediatric patients with idiopathic calcium urolithiasis. Arch Med Res. 2009; 40:369-73. doi: 10.1016/j.arcmed.2009.05.004.

12. Barnett C, Nazzal L, Goldfarb DS, Blaser MJ. The Presence of Oxalobacter formigenes in the Microbiome of Healthy Young Adults. J Urol. 2016;195:499-506. doi: 10.1016/j. juro.2015.08.070.

13. Turroni S, Bendazzoli C, Dipalo SC, Candela M, Vitali B, Gotti R, et al. Oxalate-degrading activity in Bifidobacterium animalis subsp. lactis: impact of acidic conditions on the transcriptional levels of the oxalyl coenzyme A (CoA) decarboxylase and formyl-CoA transferase genes. Appl Environ Microbiol. 2010;76:5609-20. doi: 10.1128/ AEM.00844-10.

14. Gomathi S, Sasikumar P, Anbazhagan K, Sasikumar S, Kavitha M, Selvi MS, et al. Screening of indigenous oxalate degrading lactic acid bacteria from human faeces and South Indian fermented foods: assessment of probiotic potential. ScientificWorldJournal. 2014; 2014:648059. doi: $10.1155 / 2014 / 648059$

15. Stepanova N, Tostanova G, Stashevska N, Dzyubenko N, Sergiychuk T, Akulenko A. The antibiotic prophylaxis affect on the colon oxalobacter formigenes colonization in patients with recurrent pyelonephritis and hyperoxaluria (pilot study). Nephrol Dial Transplant. 2017;32:iii432-3. doi: $10.1093 / \mathrm{ndt} / \mathrm{gfx} 160 . \mathrm{MP} 013$

16. Tasian GE, Jemielita T, Goldfarb DS, Copelovitch L, Gerber JS, Wu Q, et al. Oral Antibiotic Exposure and Kidney Stone Disease. J Am Soc Nephrol. 2018;29:1731-40. doi: 10.1681/ ASN.2017111213.

17. Kharlamb V, Schelker J, Francois F, Jiang J, Holmes RP, Goldfarb DS. Oral antibiotic treatment of Helicobacter pylori leads to persistently reduced intestinal colonization rates with Oxalobacter formigenes. J Endourol. 2011;25:1781-5. doi: 10.1089/end.2011.0243.

18. Stepanova N, Driyanska V, Korol L, Mihal L, Savchenko $\mathrm{V}$. The effects of gut indigenous microbiota on intensity of oxidative stress and the cytokine immunity in women with recurrent pyelonephritis. Medicni Perspektivi (Medical Perspectives). 2018;23:129-135. doi: 10.26641/23070404.2018.1(part1).127251.

19. Hodgkinson A. Oxalic acid in biology and medicine. London: Academic Press; 1977.

20. Mogna L, Pane M, Nicola S, Raiteri E. Screening of different probiotic strains for their in vitro ability to metabolise oxalates: any prospective use in humans? J Clin Gastroenterol. 2014; 48 Suppl 1:S91-5. doi: 10.1097/ MCG.0000000000000228.

21. Allison MJ, Cook HM, Milne DB, Gallagher S, Clayman RV. Oxalate degradation by gastrointestinal bacteria from humans. J Nutr. 1986; 116(3):455-60. doi: 10.1093/ jn/116.3.455

22. Atlas RM. Handbook of microbiological media. 4th ed. Taylor and Francis Group LLC; 2010.

23. Demikhov O, Dehtyarova I, Demikhova N. Actual aspects of public health policy formation on the example of Ukraine. BJMS. 2020;19:358-64. doi: 10.3329/bjms. v19i3.45850.

24. Perinpam M, Enders FT, Mara KC, Vaughan LE, Mehta RA, Voskoboev N, et al. Plasma oxalate in relation to eGFR in patients with primary hyperoxaluria, enteric hyperoxaluria and urinary stone disease. Clin Biochem. 2017; 50:10141019. doi: 10.1016/j.clinbiochem.2017.07.017.

25. Stepanova N, Driianska V, Kolesnyk M. Hyperoxaluriaassociated cytokines dysregulation in women with recurrent pyelonephritis. Int Med J. 2020; 25:783-790.

26. Marangella M, Petrarulo M, Mandolfo S. Plasma profiles and dialysis kinetics of oxalate in patients receiving hemodialysis. Nephron. 1992;60:74-80. doi: $10.1159 / 000186708$

27. Mydlík M, Derzsiová K. Renal replacement therapy and secondary hyperoxalemia in chronic renal failure. Kidney Int Suppl. 2001;78:S304-7.

28. Stadlbauer V, Horvath A, Ribitsch W, Schmerböck B, Schilcher G, Lemesch S, et al. Structural and functional differences in gut microbiome composition in patients undergoing haemodialysis or peritoneal dialysis. Sci Rep. 2019;9:8522. doi: 10.1038/s41598-019-43263-x.

29. Georgieva R, Yocheva L, Tserovska L, Zhelezova G, Stefanova N, Atanasova A, et al. Antimicrobial activity and antibiotic susceptibility of Lactobacillus and Bifidobacterium spp. intended for use as starter and probiotic cultures. Biotechnol Biotechnol Equip. 2015; 29:84-91. doi: 10.1080/13102818.2014.987450.

30. Hu J, Zhong X, Yan J, Zhou D, Qin D, Xiao X, et al. Highthroughput sequencing analysis of intestinal flora changes 
in ESRD and CKD patients. BMC Nephrol. 2020; 21:12. doi: 10.1186/s12882-019-1668-4.

31. Vasylchenko VS, Korol LV, Kuchmenko OB, Stepanova NM. The oxidative status in patients with chronic kidney disease. Ukrainian Bioch J. 2020; 92:70-7. doi: 10.15407/ ubj92.05.070.

32. Hatch M, Freel RW. A human strain of Oxalobacter (HC1) promotes enteric oxalate secretion in the small intestine of mice and reduces urinary oxalate excretion. Urolithiasis. 2013;41:379-84. doi: 10.1007/s00240-013-0601-8.

33. Whittamore JM, Hatch M. The role of intestinal oxalate transport in hyperoxaluria and the formation of kidney stones in animals and man. Urolithiasisю 2017;45:89-108. doi: $10.1007 / \mathrm{s} 00240-016-0952-z$.

34. Jiang Z, Asplin JR, Evan AP, Rajendran VM, Velazquez $\mathrm{H}$, Nottoli TP, Binder HJ, Aronson PS. Calcium oxalate urolithiasis in mice lacking anion transporter Slc26a6. Nat Genet. 2006;38:474-8. doi: 10.1038/ng1762.

35. Arvans D, Jung YC, Antonopoulos D, Koval J, Granja I, Bashir M, et al. Oxalobacter formigenes-derived bioactive factors stimulate oxalate transport by intestinal epithelial cells. J Am Soc Nephrol. 2017; 28:876-87. doi: 10.1681/ ASN.2016020132. 